\title{
TWIST and ovarian cancer stem cells: implications for chemoresistance and metastasis
}

\author{
Sudhakar V. Nuti ${ }^{1}$, Gil Mor ${ }^{1}$, Peiyao $\mathbf{L i}^{2}$ and Gang Yin ${ }^{2}$ \\ ${ }^{1}$ Department of Obstetrics, Gynecology and Reproductive Sciences, Yale School of Medicine, New Haven, CT, USA \\ 2 Department of Pathology, School of Basic Medicine, Central South University, Changsha, Hunan, China \\ Correspondence to: Gil Mor, email: gil.mor@yale.edu \\ Gang Yin, email: gang.yin@csu.edu.cn
}

Keywords: ovarian cancer stem cells, EMT, MET, TWIST1, chemoresistance

Received: July 08, 2014

Accepted: September 02, 2014

Published: September 03, 2014

This is an open-access article distributed under the terms of the Creative Commons Attribution License, which permits unrestricted use, distribution, and reproduction in any medium, provided the original author and source are credited.

\section{ABSTRACT}

The transcription factor TWIST1 is a highly evolutionally conserved basic Helix-Loop-Helix (bHLH) transcription factor that functions as a master regulator of gastrulation and mesodermal development. Although TWIST1 was initially associated with embryo development, an increasing number of studies have shown TWIST1 role in the regulation of tissue homeostasis, primarily as a regulator of inflammation. More recently, TWIST1 has been found to be involved in the process of tumor metastasis through the regulation of Epithelial Mesenchymal Transition (EMT). The objective of this review is to examine the normal functions of TWIST1 and its role in tumor development, with a particular focus on ovarian cancer. We discuss the potential role of TWIST1 in the context of ovarian cancer stem cells and its influence in the process of tumor formation.

\section{INTRODUCTION}

TWIST1 is a highly evolutionally conserved basic Helix-Loop-Helix (bHLH) transcriptional factor that functions as a master regulator of gastrulation and mesodermal development [1-4]. It has been implicated in the differentiation of multiple cell lineages, including muscle, cartilage, and osteogenic cells [5-7]. It has been shown that mice lacking TWIST1 died at E10.5, confirming its importance in development and differentiation[8]. Moreover, TWIST1 has been shown to be important in the regulation of programmed cell death and inflammation $[4,9]$, and it regulates genes that are essential for morphogenesis and cell migration [10].

In bHLH proteins, a basic DNA-binding domain is followed by two amphipathic $\alpha$-helices separated by an inter-helical loop.[11] $\alpha$-Helices are required for protein dimerization, which is a prerequisite for DNA-binding. The DNA-binding domain is able to recognize regulatory elements containing the hexanucleotide sequence (CANNTG), known as an E-box. The E-boxes are present in the regulatory elements of many lineage-specific genes, which accounts for the numerous pathways regulated by these transcription factors $[12,13]$. bHLH proteins form either homodimers or heterodimers in the transcription process. The formation of a heterodimer plays a key role in regulating the transcriptional activity of a particular bHLH protein leading to an increase or decrease in its activity [14]. The bHLH transcription factors are traditionally classified into three subclasses: the ubiquitous Class A bHLH factors, which include HEB, E2-2 and E proteins (E12/E47); Class B, which comprises bHLH proteins that have specificity in tissue expression and form dimmers with class A molecules; and Class $\mathrm{C}$, which do not form heterodimers with either class A or class B proteins [15]. The Twist proteins fall into a subfamily of the Class B bHLH factors and form heterodimers with E12 and E47 $[16,17]$. Homo sapiens TWIST1 gene is mapped to $7 \mathrm{q} 21.2$ and it contains two exons and one intron [18].

As indicated above, drosophila twist mutants fail to gastrulate, demonstrating its necessity for mesoderm differentiation and morphogenetic movement during gastrulation[19]. Subsequently, the important roles of TWIST1 in development have been further elucidated by several studies [20,21]. 


\section{TWIST1 and Normal Development}

The discovery of twist lies in the investigation of morphogenesis. Simpson et al., building off of work by Lohs-Schardin and colleagues [22], who first isolated mutants of twist and discovered its effect on embryonic polarity and segmentation, found that the twist gene was involved in establishing the dorsoventral pattern of the Drosophila embryo [23]. Thereafter, Thisse et al. published a series of seminal papers further characterizing twist gene function in morphogenesis $[1,24]$. Murre et al. proposed that twist encoded a basic helix loop helix (bHLH) transcription factor [25], which was subsequently confirmed by Wolf et al [11]. Recently, several groups reported on the human H-twist gene location, sequence, and its preliminary function in humans, and confirmed the findings from the animal studies showing that TWIST plays a role in embryonic development and that it encodes a bHLH protein that is $96 \%$ similar to the murine $M$-twist counterpart [26, 27]. In addition, it was shown that TWIST is highly expressed in embryos but not in adult tissues [28] and Doxorubicin can also affect the expression of TWIST to inhibit cellular differentiation pathways [29]. These early studies set the stage for its role in cancer stem cells and possibly drug resistance.

Given the essential role of the twist gene and TWIST transcription factor in development [20, 21], many abnormalities result when their functions go awry. In particular, germ-line mutations of the coding sequence of the TWIST1 gene can cause many complications. The most prominent manifestation of such complications is craniosynostosis - the premature fusion of one or more of the sutures between the bones of the skull, as found in conditions such as Saethre-Chotzen syndrome $[18,30]$ and Baller-Gerold syndrome [31].

\section{TWIST1 as a Modulator of Inflammation}

Inflammation is a critical biological process necessary for tissue repair, defense against microorganisms, and cell renewal. However, an uncontrolled inflammatory process could be detrimental for tissue homeostasis, leading to pathologic conditions, including cancer [32]. Consequently, the control of inflammation is critical to maintain the appropriate balance between defense of the organism and prevention of chronic inflammation. In addition to its role in embryogenesis, TWIST1 has been found to be a key regulator in the inflammatory processes. Initial studies have shown that TWIST1 is a major regulator of the NFKB signaling pathway [33]. TWIST1 has been shown to function as a modulator of $\mathrm{NF \kappa B}$ by preventing the induction of pro-inflammatory cytokines $[34,35]$. Sosic et al. first observed that upon treatment with tumor necrosis factor-alpha (TNF $\alpha)$, TWIST1 expression was associated with inhibition of cytokines by blocking the NFkB signaling pathway [36]. They proposed that TWIST1 regulates cytokine signaling by establishing a negative feedback loop that represses the NFKB-dependent cytokine pathway. Notably, the inflammatory pathway can also be affected by TWIST binding to NF- $\mathrm{kB}$ through a non-HLH mechanism [37]. Sharif et al. then reported the interaction between Type I interferons (IFNs), TWIST1, and the NFאB pathway [34]. Type I IFNs are pleiotropic cytokines and have immune regulatory functions by controlling the production of pro-inflammatory cytokines. The regulatory function of Type I IFNs has been shown in several patho-physiological settings such as delayed type hypersensitivity reactions, host defense to Listeria monocytogenes, and suppression of endotoxin-induced mortality [38] [39]. The mechanisms underlying the suppressive effects of Type I IFNs are not well understood but include the suppression of TNF $\alpha$ production. Sharif et al. found that Type I IFNs suppressed the production of TNF $\alpha$ through the regulation of the expression of the receptor tyrosine kinase Axl and downstream induction of TWIST1 [39]. TWIST1 binds to E-box elements in the TNF $\alpha$ promoter and suppresses NFkB-dependent transcription. Studies from our laboratory have shown that TWIST1 negatively regulates NFKB-dependent cytokine production through the regulation of has-miR-199a, which subsequently inhibits IKK $\beta$ and therefore NFKB activity [35]. The expression of IKK $\beta$ has been associated with the differential response to TNF- $\alpha$ [40]; therefore, regulation of IKK $\beta$ may switch the response of the TNF $\alpha$ from proinflammatory into pro-apoptotic or anti-inflammatory [41].

TWIST1 also plays an important role in regulating the function and differentiation of immune cells, particularly T helper 1 (Th1) cells. Niesner et al. showed that TWIST1 is expressed in Th1 effector memory (EM) cells, as it is induced by IL-12 via STAT4 and T cell receptor (TCR) signaling, which resulted in activation of Nuclear Factor of activated T-cells (NFAT) and NF$\kappa \mathrm{B}$ [42]. Interestingly, they found that expression of TWIST1 in Th1 lymphocytes limited the expression of the cytokines interferon-gamma (IFN $\gamma$ ), IL-2, and TNF $\alpha$, and ameliorated Th1-mediated immunopathology in delayedtype hypersensitivity and antigen-induced arthritis. Pham et al. further elucidated the role of TWIST1 in Th1 cell development. They found that TWIST1 decreased IFN- $\gamma$ production in Th1 cells by impairing the activity of the Th1 transcription factor network T-bet, STAT4, and Runx3 [43]. They also observed that TWIST1 is a key player in controlling - specifically limiting - both cell-mediated and humoral immunity [44]. In these studies, they were able to identify a feedback loop where cytokines, including IL-6, induced the STAT3-dependent expression of TWIST1 that repressed the transcription of the Il6ra, thereby limiting STAT3 activation and IL-6 responsiveness. The latter, in particular, limits the development of $\mathrm{T}$ follicular helper (Tfh) cells and T helper 17 (Th17) cells in vivo. 
Another area of TWIST1's influence on inflammation is in adipose tissue [45]. Pettersson et al. described TWIST1's role in the inflammation of human white adipose tissue (WAT) by regulating at the transcriptional level the expression and secretion of inflammatory adipokines and fatty acid oxidation [46]. They also showed that TWIST1 levels are influenced by body weight status and weight loss [47]. Specifically, they found that low TWIST1 expression in human WAT was associated with obesity, insulin resistance, and increased secretion of inflammatory adipokines. They postulated that this effect may be due to an increased sensitively to TNFa's effects. All these results strongly support the critical role of TWIST1 maintaining the delicate balance during the inflammatory response and, furthermore, its importance in pathologic conditions associated with deregulation of inflammation, such as cancer.

\section{TWIST1 and Cancer}

A growing number of studies have reported that TWIST1 is overexpressed in a variety of cancers, including breast cancer [48], gastric cancer [49, 50], colorectal carcinoma $[15,51]$, hepatocellular carcinoma $[52,53]$, prostate cancer $[54,55]$, bladder cancer $[56$, 57], nasopharyngeal carcinoma [58], head and neck squamous cell carcinoma [59, 60], esophageal cancer [61], endometrial cancer [62], and ovarian cancer [35, 41, 63, 64]. TWIST1's role in tumor formation and progression is an active area of research and its important role is becoming increasingly evident.

TWIST association with cancer has focused mainly on its potential role as a regulator of inflammation and in the generation of cancer cells with metastatic capacity. TWIST1 has been shown to play an important role in the process of Epithelial Mesenchymal Transition (EMT), which correlates with higher cancer aggressiveness and poor survival rates [65].

\section{Epithelial Mesenchymal Transition and the Process of Metastasis}

The epithelial-mesenchymal transition (EMT) converts epithelial cancer cells into mesenchymal cancer cells with migratory capability and consequently the capacity to invade and metastasize. EMT is characterized by the loss of epithelial polarity and differentiation markers (such as E-cadherin and $\beta$-catenin) and the gain of mesenchymal markers (such as $\mathrm{N}$-cadherin and vimentin) $[66,67]$. Cancer cells with a mesenchymal phenotype are capable of migrating away from their primary tumor, interacting with stromal cells, invading their adjacent tissues, and intravasating into the lymphatic system and/ or blood stream and settling into secondary tumor sites $[68,69]$.
As noted above, TWIST1 overexpression has been reported in a variety of cancers, and many observations have highlighted the role of TWIST1 in promoting cancer cell EMT and metastasis. Yang J et al. found that TWIST1 plays an important role in breast cancer EMT and metastasis [48]. They showed that suppression of TWIST1 by siRNA in highly metastatic mammary tumor cells specifically inhibits the cells' ability to metastasize from the mammary gland to the lung. Ectopic expression of TWIST1 in the epithelial cancer cells results in loss of E-cadherin-mediated cell-cell adhesion, gain of mesenchymal markers, and induction of cell motility, implicating that Twist1 contributes to metastasis by promoting the expression of genes associated with the process of EMT. Yang Z et al. showed that TWIST1 regulates cell motility and invasion in gastric cancer cell lines, possibly through the $\mathrm{N}$-cadherin and fibronectin production [50]. Luo GQ et al. then demonstrated that TWIST1 promotes the migration and invasion ability of gastric cancer cells through EMT [49]. Fan $\mathrm{XJ}$ et al. investigated the expression of TWIST1 and E-cadherin by immunohistochemistry in colorectal cancers [15]. They showed that expression of TWIST1 correlated with decreased membranous expression of E-cadherin. Importantly, TWIST1 up-regulation in the primary tumor had high correlation with the presence of metastatic tumors. Lee TK et al. revealed that TWIST1 overexpression correlated with hepatocellular carcinoma (HCC) metastasis, and high levels of TWIST1 mRNA level was found in metastatic HCC cell lines [52]. Further studies on the HCC cell lines showed that TWIST1 was able to induce EMT, which was correlated with increased HCC cell invasiveness [52]. Matsuo N et al. similarly found that TWIST1 induces a migratory effect in hepatocellular carcinoma by causing EMT [70].

Several studies have evaluated TWIST1 expression in primary tumors and revealed a correlation between TWIST1 expression and metastatic disease. Kwok WK, et al. found that TWIST1 was highly expressed in a majority of prostate cancer patients, and TWIST1 expression levels were positively correlated with Gleason grading and metastasis, suggesting its major role in the progression of prostate cancer [54]. Zhang Z, et al. showed that TWIST1 expression was higher in bladder cancer tissues compared with nonmalignant tissues and that increased TWIST1 expression levels were correlated with high grade and advanced stage tumors, indicating its role in the in the development and progression of bladder cancer [57]. In addition, they showed that TWIST1 was significantly higher in the metastatic lesions compared with the primary site, and the increased TWIST1 expression in bladder cancer was associated with decreased expression of E-cadherin. Shen $\mathrm{CH}$ et al. showed that TWIST1 may act upstream of E-cadherin, which can regulate the expression of beta-catenin, providing further evidence that EMT factors TWIST1, E-cadherin, and beta-catenin play 
important roles in the metastatic progression of bladder cancer [56]. Horikawa T et al. suggested that the induction of TWIST1 directly contributes to the metastatic nature of nasopharyngeal carcinoma [59]. Yu L et al. (2012) revealed that the overexpression of TWIST1 plays an important role in the metastasis of hypopharyngeal tumors [60]. Since TWIST1 correlated with EMT and c-fos and MMP-9 expression, they concluded that the TWIST/cfos/MMP-9 pathway might play an important role in the metastasis of cells.

Yang $\mathrm{MH}$ et al. showed that TWIST1 is directly regulated by HIF-1 $\alpha$ [71]. Under hypoxic conditions, HIF- $1 \alpha$ is stabilized and promotes EMT and metastatic phenotypes through the regulation of TWIST1 by binding directly to the hypoxia-response element (HRE) in the TWIST1 proximal promoter. In another seminal paper, Yang $\mathrm{MH}$ et al. showed that TWIST1 regulates the polycomb-group protein Bmil and that both TWIST1 and Bmil were mutually essential to promote EMT and repress expression of E-cadherin and p16INK4a in head and neck cancers, with the up-regulation of both proteins conferring the worst prognosis for patients [72]. In addition, Cheng et al. showed the activation of STAT3 by Il-6 induced TWIST1 expression at both the protein and mRNA levels, and thereby promoting metastasis [4].

\section{Chemoresistance and Angiogenesis}

Chemoresistance is a major limitation on the successful treatment of all types of cancers. Therefore, identification of the molecular mechanisms associated with chemoresistance is a critical step toward preventing recurrent disease, the clinical outcome associated with the survival of cancer cells to chemotherapy [73]. Emerging evidence suggests that TWIST1 plays an important role in the chemoresistance of cancer cells. Wang et al. found that up regulation of TWIST1 was responsible for the development of acquired paclitaxel-resistance in nasopharyngeal carcinoma cells, and ectopic expression of TWIST1 led to increased resistance to microtubuledisrupting agents, including paclitaxel and vincristine [74]. Zhang X et al. suggested that the TWIST1-induced taxol resistance is mediated through protection against apoptosis and TWIST1-mediated taxol resistance may be regulated through its positive involvement with the Akt pathway [58]. Pham CG et al. found that TWIST1 plays an important role in NF- $\mathrm{BB}$-dependent chemoresistance [75].

In addition to inducing chemoresistant properties, TWIST1 also has a role in cancer angiogenesis. Mironchik et al. showed that stable over-expression of TWIST1 in breast cancer cells increased VEGF synthesis [76]. Furthermore, in vivo tumors with over-expressed TWIST1 exhibited higher vascular volume and vascular permeability. Niu et al. then showed that the high expression of TWIST1 in HCC was associated with hgher microvessel density and an up-regulation of VEGF and
$\mathrm{N}$-cadherin [53]. Thus, TWIST1 induces angiogenesis in many cancers.

\section{TWIST1 and Ovarian Cancer}

One of the first reports linking TWIST1 and ovarian cancer was the study from Kajiyama and colleagues [77]. They found that TWIST1 expression predicts poor clinical outcomes in patients with clear cell carcinoma (CCC) of the ovary, suggesting that TWIST1 may play a critical role in the progression of CCC. They proposed that TWIST1 expression in the tumor could be used as a potentially prognostic indicator. Hosono et al. further evaluated the value of TWIST1 as a prognostic marker in patients with epithelial ovarian carcinoma (EOC) and reached a similar conclusion as that reported by Kajiyama et al.[63]. They found that positive TWIST1 expression significantly predicted poorer progression-free survival and overall survival and that in a multivariate analysis, it was the only independent prognostic factor for survival.

Since then, several studies have been conducted to elucidate the function of TWIST1 in ovarian carcinomas. Two main areas of TWIST1 influence have emerged metastasis and chemoresistance. As will be discussed below, cancer stem cells - in this case ovarian cancer stem cells - play a large part in both cancer progression and chemoresistance. We will discuss first the broader findings on the role of TWIST1 in ovarian cancer and then we will review the role of TWIST1 in ovarian cancer stem cells.

As described for other solid tumors, TWIST1 is thought to play an important role in the metastatic process of ovarian cancer. Terauchi et al. showed that there was a correlation between TWIST1 expression and epithelial ovarian cancer (EOC) cellular morphology [64]. Specifically, they showed that the suppression of TWIST1 expression in these cells alters the cellular morphology from a mesenchymal, fibroblastic, motile phenotype to an epithelial phenotype while concurrently inhibiting the adhesion of these cells to mesothelial monolayers. This was one of the first indications of the role of Twist in the multistep EMT process of peritoneal metastasis dissemination in ovarian cancer. Yoshida et al. then showed in ovarian surface epithelium (OSE) tumors that TWIST1 expression increased step-wise in benign, borderline, and malignant tumors [78]. Elloul et al. similarly found that TWIST1 expression was significantly higher in solid ovarian cancer metastases compared to primary carcinomas and effusions[79]. Wang et al. explored TWIST1's regulation of E-cadherin showing that ovarian carcinomas, compared with normal ovary tissues, had a greater abundance of TWIST1 expression and a decrease in E-cadherin expression [80]. When Twist expression was silenced, however, E-cadherin expression then increased. As we have seen in other cancers, the Twist-E-cadherin axis of metastasis may be implicated in ovarian cancer as well. 
While the control of metastasis is one area of TWIST1's involvement in ovarian cancer, it is also involved in another important phenomenon chemoresistance. One of the first papers that chronicled the effects of TWIST1 in ovarian cancer was by Wang et al., who showed that TWIST1 expression was associated with taxol resistance in ovarian cancer cell lines, indicating a possible larger role in the "development of resistance to certain microtubule-disrupting agents in human cancer" [74]. Additional studies were conducted by Li et al., who demonstrated that TWIST1 was highly upregulated in cisplatin-resistant ovarian cancer cells as compared to cisplatin-sensitive cells [81]. Similarly, we found a significant increase of Twist expression in an animal model of recurrence. Tumors from recurrent disease after treatment with Paclitaxel had higher levels of TWIST1 as well as of genes associated with mesenchymal differentiation (Slug, vimentin) and stemness (ALDH1, KLF4 MyD88) [73]

\section{Ovarian Cancer Stem Cells}

Hematopoietic cancers and solid tumors contain a population of cells that possess the capacity to selfrenew and to produce the heterogeneous lineage of cancer cells that comprise the whole tumor $[82,83]$. These cells have been defined as cancer stem cells (CSCs) and are characterized by unique plasticity and differentiation potential. Current evidence suggests that CSCs are the putative mediators of chemoresistance and tumor progression [84-86]. It is thought that CSCs are able to survive conventional chemotherapeutic treatments, which usually target fast-dividing cells and give rise to recurrent tumors that are more chemoresistant and more aggressive [87-89].

Using CD44 as a marker, our group identified Epithelial Ovarian Cancer (EOC) stem cells based on their capacity to recreate the original tumor when injected into mice [90-94]. We have fully characterized the molecular phenotype of these cells $[90,91,95]$ and demonstrated their plasticity - they are able to differentiate and lose stemness markers in vitro and in vivo and, more importantly, are able to differentiate into endothelial cells $[91,96]$. Indeed, we find that the presence of these cells is associated with shorter progression-free survival in EOC patients [94]. Our findings are in line with other studies that have shown the existence of tumor-initiating cells (TICs) in EOC through the use of different markers suggestive of the heterogeneity of the disease [90, 97101]. Nevertheless, there is a consensus that CD44+ EOC cells represent the chemoresistant phenotype [97-99, 102104].

Our most recent data identified an additional differentiation potential in the EOC stem cells. As explained in more detail below, by undergoing EMT, these cells acquire markers and behavioral attributes of mesenchymal cells, including the capacity to form compact spheroids and increased migratory and invasive capacity [105].This suggests that the EOC stem cells are the source of metastatic disease.

\section{Spread of Ovarian Cancer}

Metastatic ovarian cancer is characterized by carcinomatosis in the abdomen and pelvis. It usually spreads locally and rarely through the circulation [106, 107]. This suggests that ovarian cancer cells are able to lose cell-to-cell contact and shed into the peritoneal cavity to establish metastatic disease [108]. As usually observed in ascitic fluid from ovarian cancer patients, cancer cells in the peritoneal cavity often aggregate and form spheroidlike structures, which can subsequently implant throughout the abdomen with a varying extent of peritoneal invasion [109]. Our studies have shown that the EOC stem cells represent the cell population that can differentiate into the spheroid-forming cells with metastatic potential. We have been able to recreate in vitro, from a pure population of EOC stem cells the process of differentiation from epithelial cells to mesenchymal spheroid cells (m-spheroid cells) similar to those observed in the ascites [35, 105]. Moreover, we showed that m-spheroid cells can revert back to an epithelial phenotype through the mesenchymalepithelial transition (MET) and give rise to epithelial cultures that have lost stemness markers [105]. We hypothesized that a subpopulation of EOC stem cells have the capacity to undergo EMT, acquire the capacity to migrate and invade out of the solid tumor to generate m-spheroid cells, and establish metastatic disease (Fig. 1).

\section{Epithelial-Mesenchymal Transition and Metastasis in Ovarian Cancer}

Epithelial cells are characterized by the propensity for cell-cell adhesion, planar and apical-basal polarity and lack of mobility [34, 35]. As stated above, EMT is a process by which epithelial cells lose these characteristics and acquire mesenchymal properties, including the capacity to migrate and invade [110]. Thus, in cancer, EMT has been associated with metastasis [111]. There are multiple factors inducing EMT in human solid tumors including, but not limited to, inflammation, hypoxia, fibrosis, necrosis, apoptosis, senescence, and DNA damage [111-114]. Therefore, it is not possible to define a canonical EMT pathway; neither has it been possible to define the target cells, which have the capacity to respond to these signals and undergo transformation.

Epithelial ovarian cancer stem cells maintain the epithelial characteristics of epithelial tumors; however, they lack the capacity of migration and therefore metastasis [105]. We hypothesized that within the cancer stem cells, a small fraction of cells could acquire 
the potential for migration and tumor metastasis - "the metastatic ovarian cancer stem cells". Recently, we described, in addition to the epithelial ovarian cancer stem cells and the EOC cells, the characterization of a third type of ovarian cancer cells with migratory capacity: migratory ovarian cancer stem cells (mOCS cells) (Fig 1) [105]. Most importantly, the differentiation of EOC stem cells with epithelial phenotype to these mOCSs with mesenchymal characteristics is associated with the upregulation of the transcription factor TWIST1 [35]. The following novel insights exemplify the importance and potential link between cancer stem cells and TWIST1 in the progression of ovarian cancer, and serve as a framework for understanding the role of TWIST1 in ovarian cancer.

Studies from our lab have demonstrated that TWIST1 is a major regulator of EOC 'stemness' by controlling stem cell differentiation through the positive regulation of miRNAs miR-199a and miR-214 [41] [35]. These miRNAs are inhibitors of PTEN and IKK $\beta$, therefore controlling cell proliferation, apoptosis, and inflammation. All these aspects are important for maintaining the characteristics of cancer stem cells [41]. Interestingly, TWIST1 expression is tightly controlled in EOC stem cells in order to maintain their epithelial phenotype. We found that EOC stem cells have an active mechanism to prevent the accumulation of TWIST1 protein even in the presence of high levels of mRNA,

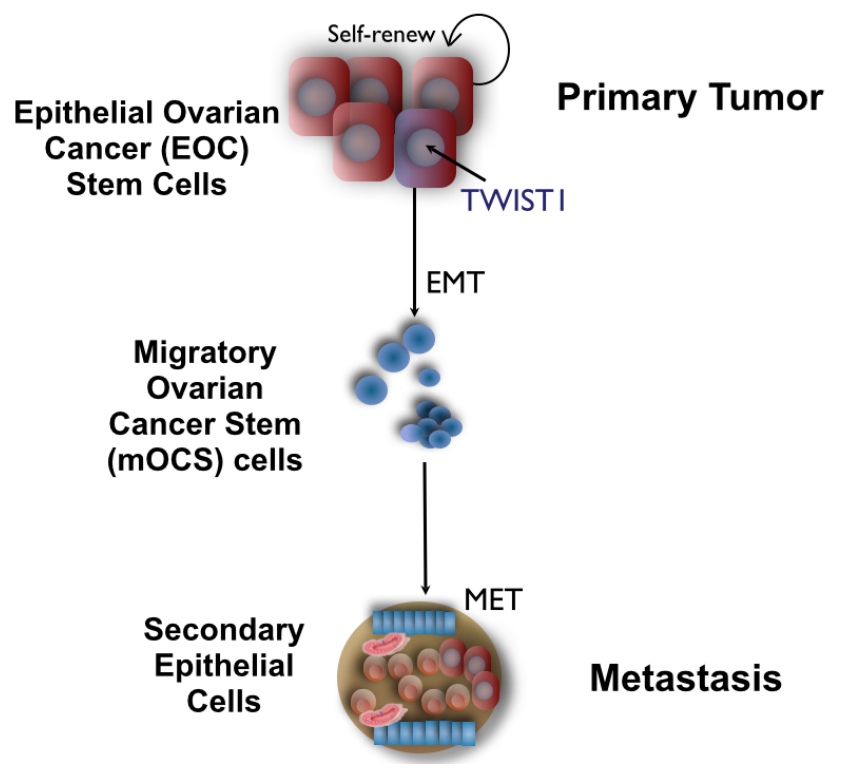

Figure 1: Role of TWIST1 on Epithelial Mesenchymal Transition of Epithelial Ovarian Cancer Stem cells. TWIST1 expression in epithelial ovarian cancer stem cells promotes their differentiation into mesenchymal cells with cancer stem cells properties and migratory capacity. Once attached to a different region of the peritoneal cavity these cells undergo MET and establish a metastatic tumor with epithelial characteristics.

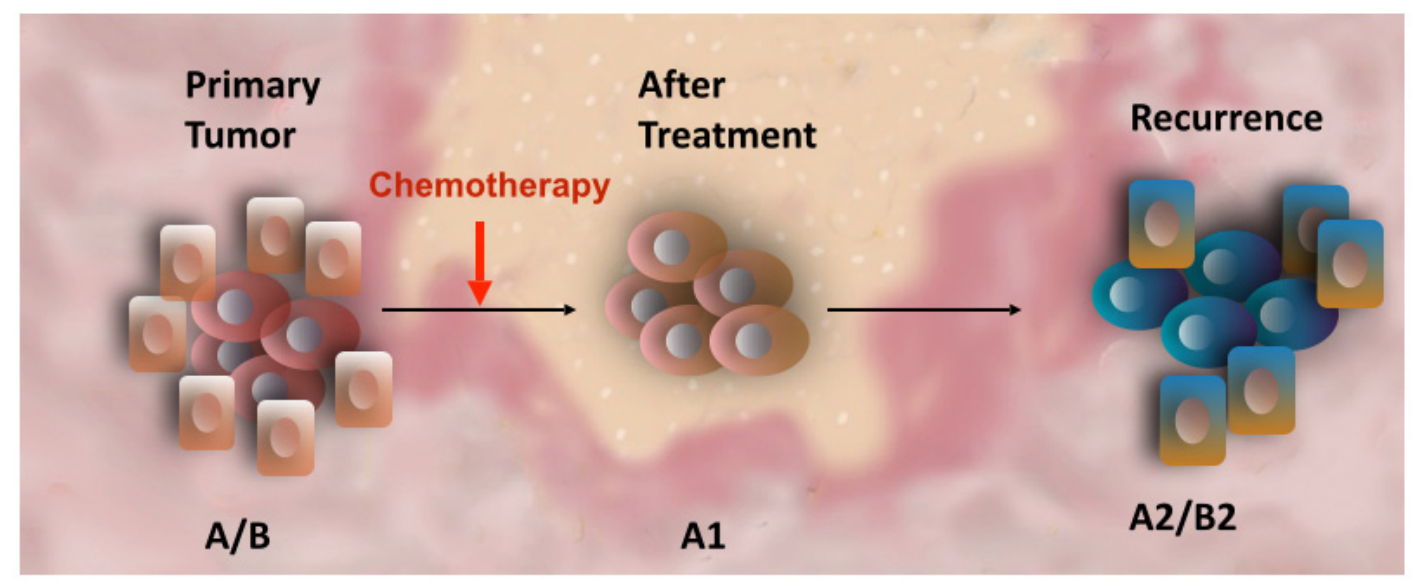

Figure 2: Effect of Chemotherapy on Cancer Stem Cells. Primary tumors are heterogeneous made up by a hierarchy of cancer cells (A/B). Conventional chemotherapy targets the fast dividing cancer cells (B) leaving the chemo-resistant cancer stem cells (A). However, the cells composing the residual tumors revealed different molecular characteristics than those observed on the original cancer stem cells (A1). Consequently, the secondary tumor is different from the primary disease and will respond differently to therapy. 
which involves the ubiquitin-proteasome system. However, when the levels of TWIST1 protein increase, we found that EOC stem cells differentiate into the migratory ovarian cancer stem cells (mOSC cells) with mesenchymal characteristics [105]. While TWIST1 was constitutively degraded in EOC stem cells, E12 expression stabilized TWIST1 protein expression. The expression of both TWIST1 and E12 were induced by hypoxia/ HIF-1, yet the lack of TWIST1 in EOC stem cells in the presence of hypoxia prevented EMT, which illuminates the essential role of TWIST1 in the regulation of ovarian cancer differentiation.

Kajiyama et al. established an ovarian cancer cell line that is resistant to paclitaxel and found that these cells displayed high levels TWIST1 protein and had a greater migratory and metastatic potential compared to cells that are paclitaxel sensitive [115]. Latifi et al. also observed that cisplatin induced EMT in ovarian cancer cells, where TWIST1 expression was significantly increased in response to the chemotherapy and was associated with increased migration of the cells [116].

Thus, based on these studies and our own, we could postulate that chemo-resistant cells undergo EMT in response to chemotherapy as result of upregulation of TWIST1 expression. Indeed, we recently demonstrated that Paclitaxel treatment can induce molecular modifications on EOC stem cells enhancing the acquisition of mesenchymal characteristics while maintaining their stemness potential [73]. Our findings suggest that chemotherapy does not only enriches for putative EOC stem cells, but the treatment can also induce specific phenotypic modifications in the surviving EOC stem cells (Fig. 2). These changes might contribute to recurrence where the cells are more aggressive and also show a higher degree of chemoresistance. Using in vitro and in vivo models we found the expression of TWIST1 and other EMT genes in the EOC stem cells that survive Paclitaxel treatment. These molecular changes might provide the original EOC stem cells the capacity to migrate and establish multiple metastatic sites, a characteristic of recurrent disease [73].

Moving forward, more studies are needed to characterize the ovarian cancer stem cells before and after chemotherapy and the functionality of TWIST1 in each of these cell cohorts to understand how it functions in different cellular environments to created better targeted therapies to destroy the cancer and prevent recurrence.

\section{CONCLUSION}

Although initially identified as a transcription factor associated with embryonic development, TWIST1 may play additional roles in the regulation of tissue homeostasis. Furthermore, its role in cancer opens a field of opportunities for the development of new diagnostic tests and therapeutic modalities, with a particular focus on ovarian cancer stem cells.

\section{ACKNOWLEDGMENTS}

This study was supported in part by NIH grant RO1CA127913, the Sands Family Foundation, the Debra Levin Endowment Fund and the Discovery to Cure Program.

\section{REFERENCES}

1. Thisse B, el Messal M and Perrin-Schmitt F. The twist gene: isolation of a Drosophila zygotic gene necessary for the establishment of dorsoventral pattern. Nucleic Acids Res. 1987; 15(8):3439-3453.

2. Leptin $M$ and Grunewald B. Cell shape changes during gastrulation in Drosophila. Development. 1990; 110(1):7384.

3. Bialek P, Kern B, Yang X, Schrock M, Sosic D, Hong $\mathrm{N}, \mathrm{Wu} \mathrm{H}, \mathrm{Yu}$ K, Ornitz DM, Olson EN, Justice MJ and Karsenty G. A twist code determines the onset of osteoblast differentiation. Dev Cell. 2004; 6(3):423-435.

4. Cheng GZ, Zhang WZ, Sun M, Wang Q, Coppola D, Mansour M, Xu LM, Costanzo C, Cheng JQ and Wang LH. Twist is transcriptionally induced by activation of STAT3 and mediates STAT3 oncogenic function. J Biol Chem. 2008; 283(21):14665-14673.

5. Lee MS, Lowe G, Flanagan S, Kuchler K and Glackin CA. Human Dermo-1 has attributes similar to twist in early bone development. Bone. 2000; 27(5):591-602.

6. Lee MS, Lowe GN, Strong DD, Wergedal JE and Glackin CA. TWIST, a basic helix-loop-helix transcription factor, can regulate the human osteogenic lineage. J Cell Biochem. 1999; 75(4):566-577.

7. Ota MS, Loebel DA, O'Rourke MP, Wong N, Tsoi B and Tam PP. Twist is required for patterning the cranial nerves and maintaining the viability of mesodermal cells. Dev Dyn. 2004; 230(2):216-228.

8. Baylies MK and Bate M. twist: a myogenic switch in Drosophila. Science. 1996; 272(5267):1481-1484.

9. Cheng GZ, Zhang W and Wang LH. Regulation of cancer cell survival, migration, and invasion by Twist: AKT2 comes to interplay. Cancer Res. 2008; 68(4):957-960.

10. Soo K, O'Rourke MP, Khoo PL, Steiner KA, Wong N, Behringer RR and Tam PP. Twist function is required for the morphogenesis of the cephalic neural tube and the differentiation of the cranial neural crest cells in the mouse embryo. Dev Biol. 2002; 247(2):251-270.

11. Wolf C, Thisse C, Stoetzel C, Thisse B, Gerlinger P and Perrin-Schmitt F. The M-twist gene of Mus is expressed in subsets of mesodermal cells and is closely related to the Xenopus X-twi and the Drosophila twist genes. Dev Biol. 1991; 143(2):363-373.

12. Wilson-Rawls J, Rhee JM and Rawls A. Paraxis is a 
basic helix-loop-helix protein that positively regulates transcription through binding to specific E-box elements. J Biol Chem. 2004; 279(36):37685-37692.

13. Ellenberger T, Fass D, Arnaud M and Harrison SC. Crystal structure of transcription factor E47: E-box recognition by a basic region helix-loop-helix dimer. Genes Dev. 1994; 8(8):970-980.

14. Rose CS and Malcolm S. A TWIST in development. Trends Genet. 1997; 13(10):384-387.

15. Fan XJ, Wan XB, Yang ZL, Fu XH, Huang Y, Chen DK, Song SX, Liu Q, Xiao HY, Wang L and Wang JP. Snail promotes lymph node metastasis and Twist enhances tumor deposit formation through epithelial-mesenchymal transition in colorectal cancer. Hum Pathol. 2013; 44(2):173-180.

16. Murre C, Bain G, van Dijk MA, Engel I, Furnari BA, Massari ME, Matthews JR, Quong MW, Rivera RR and Stuiver MH. Structure and function of helix-loop-helix proteins. Biochim Biophys Acta. 1994; 1218(2):129-135.

17. Castanon I and Baylies MK. A Twist in fate: evolutionary comparison of Twist structure and function. Gene. 2002; 287(1-2):11-22.

18. Howard TD, Paznekas WA, Green ED, Chiang LC, Ma N, Ortiz de Luna RI, Garcia Delgado C, Gonzalez-Ramos M, Kline AD and Jabs EW. Mutations in TWIST, a basic helix-loop-helix transcription factor, in Saethre-Chotzen syndrome. Nat Genet. 1997; 15(1):36-41.

19. Leptin M. twist and snail as positive and negative regulators during Drosophila mesoderm development. Genes Dev. 1991; 5(9):1568-1576.

20. Barnes RM and Firulli AB. A twist of insight - the role of Twist-family bHLH factors in development. Int J Dev Biol. 2009; 53(7):909-924.

21. Chen ZF and Behringer RR. twist is required in head mesenchyme for cranial neural tube morphogenesis. Genes Dev. 1995; 9(6):686-699.

22. Lohs-Schardin $M$, Cremer $C$ and Nusslein-Volhard C. A fate map for the larval epidermis of Drosophila melanogaster: localized cuticle defects following irradiation of the blastoderm with an ultraviolet laser microbeam. Dev Biol. 1979; 73(2):239-255.

23. Simpson P. Maternal-Zygotic Gene Interactions during Formation of the Dorsoventral Pattern in Drosophila Embryos. Genetics. 1983; 105(3):615-632.

24. Thisse B, Stoetzel C, Gorostiza-Thisse C and Perrin-Schmitt F. Sequence of the twist gene and nuclear localization of its protein in endomesodermal cells of early Drosophila embryos. EMBO J. 1988; 7(7):2175-2183.

25. Murre C, McCaw PS and Baltimore D. A new DNA binding and dimerization motif in immunoglobulin enhancer binding, daughterless, MyoD, and myc proteins. Cell. 1989; 56(5):777-783.

26. Wang SM, Coljee VW, Pignolo RJ, Rotenberg MO, Cristofalo VJ and Sierra F. Cloning of the human twist gene: its expression is retained in adult mesodermallyderived tissues. Gene. 1997; 187(1):83-92.

27. Bourgeois P, Stoetzel C, Bolcato-Bellemin AL, Mattei MG and Perrin-Schmitt F. The human H-twist gene is located at $7 \mathrm{p} 21$ and encodes a B-HLH protein that is $96 \%$ similar to its murine M-twist counterpart. Mammalian genome : official journal of the International Mammalian Genome Society. 1996; 7(12):915-917.

28. Glackin C, Winters K, Murray E and Murray S. Transcripts encoding the basic-helix-loop-helix factor twist are expressed in mouse embryos, cell lines, and adult tissues. Mol Cell Differ. 1994; 2:309-328.

29. Glackin CA, Murray EJ and Murray SS. Doxorubicin inhibits differentiation and enhances expression of the helix-loop-helix genes Id and mTwi in mouse osteoblastic cells. Biochemistry international. 1992; 28(1):67-75.

30. el Ghouzzi V, Le Merrer M, Perrin-Schmitt F, Lajeunie E, Benit P, Renier D, Bourgeois P, Bolcato-Bellemin AL, Munnich A and Bonaventure J. Mutations of the TWIST gene in the Saethre-Chotzen syndrome. Nat Genet. 1997; 15(1):42-46.

31. Seto ML, Lee SJ, Sze RW and Cunningham ML. Another TWIST on Baller-Gerold syndrome. Am J Med Genet. 2001; 104(4):323-330.

32. Karin M. Nuclear factor-kappaB in cancer development and progression. Nature. 2006; 441(7092):431-436.

33. Mantovani A. Molecular pathways linking inflammation and cancer. Curr Mol Med. 2010; 10(4):369-373.

34. Sharif MN, Sosic D, Rothlin CV, Kelly E, Lemke G, Olson EN and Ivashkiv LB. Twist mediates suppression of inflammation by type I IFNs and Axl. J Exp Med. 2006; 203(8):1891-1901.

35. Yin G, Chen R, Alvero AB, Fu HH, Holmberg J, Glackin $\mathrm{C}$, Rutherford $\mathrm{T}$ and Mor G. TWISTing stemness, inflammation and proliferation of epithelial ovarian cancer cells through MIR199A2/214. Oncogene. 2010; 29(24):3545-3553.

36. Sosic D, Richardson JA, Yu K, Ornitz DM and Olson EN. Twist regulates cytokine gene expression through a negative feedback loop that represses NF-kappaB activity. Cell. 2003; 112(2):169-180.

37. Li S, Kendall SE, Raices R, Finlay J, Covarrubias M, Liu Z, Lowe G, Lin YH, Teh YH, Leigh V, Dhillon S, Flanagan S, Aboody KS and Glackin CA. TWIST1 associates with NFkappaB subunit RELA via carboxyl-terminal WR domain to promote cell autonomous invasion through IL8 production. BMC biology. 2012; 10:73.

38. Shiota M, Izumi H, Onitsuka T, Miyamoto N, Kashiwagi E, Kidani A, Hirano G, Takahashi M, Naito S and Kohno K. Twist and p53 reciprocally regulate target genes via direct interaction. Oncogene. 2008; 27(42):5543-5553.

39. Sharif MN, Sosic D, Rothlin CV, Kelly E, Lemke G, Olson EN and Ivashkiv LB. Twist mediates suppression of inflammation by type I IFNs and Axl. J Exp Med. 2006; 
203(8):1891-1901.

40. Pikarsky E, Porat RM, Stein I, Abramovitch R, Amit S, Kasem S, Gutkovich-Pyest E, Urieli-Shoval S, Galun E and Ben-Neriah Y. NF-kappaB functions as a tumour promoter in inflammation-associated cancer. Nature. 2004; 431(7007):461-466.

41. Chen R, Alvero AB, Silasi DA, Kelly MG, Fest S, Visintin I, Leiser A, Schwartz PE, Rutherford T and Mor G. Regulation of IKKbeta by miR-199a affects NFkappaB activity in ovarian cancer cells. Oncogene. 2008; 27(34):4712-4723.

42. Niesner U, Albrecht I, Janke M, Doebis C, Loddenkemper $\mathrm{C}$, Lexberg $\mathrm{MH}$, Eulenburg $\mathrm{K}$, Kreher S, Koeck J, Baumgrass R, Bonhagen $\mathrm{K}$, Kamradt $\mathrm{T}$, Enghard P, Humrich JY, Rutz S, Schulze-Topphoff U, et al. Autoregulation of Th1-mediated inflammation by twist1. J Exp Med. 2008; 205(8):1889-1901.

43. Pham D, Vincentz JW, Firulli AB and Kaplan MH. Twist1 regulates Ifng expression in Th1 cells by interfering with Runx3 function. J Immunol. 2012; 189(2):832-840.

44. Pham D, Yu Q, Walline CC, Muthukrishnan R, Blum JS and Kaplan MH. Opposing roles of STAT4 and Dnmt3a in Th1 gene regulation. J Immunol. 2013; 191(2):902-911.

45. Dobrian AD. A tale with a Twist: a developmental gene with potential relevance for metabolic dysfunction and inflammation in adipose tissue. Front Endocrinol (Lausanne). 2012; 3:108.

46. Pettersson AT, Laurencikiene J, Mejhert N, Naslund E, Bouloumie A, Dahlman I, Arner P and Ryden M. A possible inflammatory role of twist1 in human white adipocytes. Diabetes. 2010; 59(3):564-571.

47. Pettersson AT, Mejhert N, Jernas M, Carlsson LM, Dahlman I, Laurencikiene J, Arner P and Ryden M. Twist1 in human white adipose tissue and obesity. J Clin Endocrinol Metab. 2011; 96(1):133-141.

48. Yang J, Mani SA, Donaher JL, Ramaswamy S, Itzykson RA, Come C, Savagner P, Gitelman I, Richardson A and Weinberg RA. Twist, a master regulator of morphogenesis, plays an essential role in tumor metastasis. Cell. 2004; 117(7):927-939.

49. Luo GQ, Li JH, Wen JF, Zhou YH, Hu YB and Zhou JH. Effect and mechanism of the Twist gene on invasion and metastasis of gastric carcinoma cells. World J Gastroenterol. 2008; 14(16):2487-2493.

50. Yang Z, Zhang X, Gang H, Li X, Li Z, Wang T, Han J, Luo $\mathrm{T}$, Wen $\mathrm{F}$ and $\mathrm{Wu} \mathrm{X}$. Up-regulation of gastric cancer cell invasion by Twist is accompanied by $\mathrm{N}$-cadherin and fibronectin expression. Biochem Biophys Res Commun. 2007; 358(3):925-930.

51. Gomez I, Pena C, Herrera M, Munoz C, Larriba MJ, Garcia V, Dominguez G, Silva J, Rodriguez R, Garcia de Herreros A, Bonilla F and Garcia JM. TWIST1 is expressed in colorectal carcinomas and predicts patient survival. PLoS One. 2011; 6(3):e18023.
52. Lee TK, Poon RT, Yuen AP, Ling MT, Kwok WK, Wang XH, Wong YC, Guan XY, Man K, Chau KL and Fan ST. Twist overexpression correlates with hepatocellular carcinoma metastasis through induction of epithelialmesenchymal transition. Clin Cancer Res. 2006; 12(18):5369-5376.

53. Niu RF, Zhang L, Xi GM, Wei XY, Yang Y, Shi YR and Hao XS. Up-regulation of Twist induces angiogenesis and correlates with metastasis in hepatocellular carcinoma. J Exp Clin Cancer Res. 2007; 26(3):385-394.

54. Kwok WK, Ling MT, Lee TW, Lau TC, Zhou C, Zhang X, Chua CW, Chan KW, Chan FL, Glackin C, Wong YC and Wang X. Up-regulation of TWIST in prostate cancer and its implication as a therapeutic target. Cancer Res. 2005; 65(12):5153-5162.

55. Yuen HF, Chua CW, Chan YP, Wong YC, Wang X and Chan KW. Significance of TWIST and E-cadherin expression in the metastatic progression of prostatic cancer. Histopathology. 2007; 50(5):648-658.

56. Shen $\mathrm{CH}, \mathrm{Wu}$ JD, Jou YC, Cheng MC, Lin CT, Chen PC, Tseng YS, Shi CS, Chen SY, Chang DC and Lee YR. The correlation between TWIST, E-cadherin, and beta-catenin in human bladder cancer. J BUON. 2011; 16(4):733-737.

57. Zhang Z, Xie D, Li X, Wong YC, Xin D, Guan XY, Chua CW, Leung SC, Na Y and Wang X. Significance of TWIST expression and its association with E-cadherin in bladder cancer. Hum Pathol. 2007; 38(4):598-606.

58. Zhang X, Wang Q, Ling MT, Wong YC, Leung SC and Wang X. Anti-apoptotic role of TWIST and its association with Akt pathway in mediating taxol resistance in nasopharyngeal carcinoma cells. Int J Cancer. 2007; 120(9):1891-1898.

59. Horikawa T, Yang J, Kondo S, Yoshizaki T, Joab I, Furukawa $\mathrm{M}$ and Pagano JS. Twist and epithelialmesenchymal transition are induced by the EBV oncoprotein latent membrane protein 1 and are associated with metastatic nasopharyngeal carcinoma. Cancer Res. 2007; 67(5):1970-1978.

60. Yu L, Lu S, Tian J, Ma J, Li J, Wang H and Xu W. TWIST expression in hypopharyngeal cancer and the mechanism of TWIST-induced promotion of metastasis. Oncol Rep. 2012; 27(2):416-422.

61. Yuen HF, Chan YP, Wong ML, Kwok WK, Chan KK, Lee PY, Srivastava G, Law SY, Wong YC, Wang X and Chan KW. Upregulation of Twist in oesophageal squamous cell carcinoma is associated with neoplastic transformation and distant metastasis. J Clin Pathol. 2007; 60(5):510-514.

62. Feng ZZ, Chen JW, Yang ZR, Lu GZ and Cai ZG. Expression of PTTG1 and PTEN in endometrial carcinoma: correlation with tumorigenesis and progression. Med Oncol. 2012; 29(1):304-310.

63. Hosono S, Kajiyama H, Terauchi M, Shibata K, Ino K, Nawa A and Kikkawa F. Expression of Twist increases the risk for recurrence and for poor survival in epithelial 
ovarian carcinoma patients. Br J Cancer. 2007; 96(2):314320.

64. Terauchi M, Kajiyama H, Yamashita M, Kato M, Tsukamoto H, Umezu T, Hosono S, Yamamoto E, Shibata K, Ino K, Nawa A, Nagasaka T and Kikkawa F. Possible involvement of TWIST in enhanced peritoneal metastasis of epithelial ovarian carcinoma. Clin Exp Metastasis. 2007; 24(5):329-339.

65. Watanabe O, Imamura H, Shimizu T, Kinoshita J, Okabe T, Hirano A, Yoshimatsu K, Konno S, Aiba M and Ogawa $\mathrm{K}$. Expression of twist and wnt in human breast cancer. Anticancer Res. 2004; 24(6):3851-3856.

66. Tarin D, Thompson EW and Newgreen DF. The fallacy of epithelial mesenchymal transition in neoplasia. Cancer Res. 2005; 65(14):5996-6000; discussion 6000-5991.

67. Thompson EW, Newgreen DF and Tarin D. Carcinoma invasion and metastasis: a role for epithelial-mesenchymal transition? Cancer Res. 2005; 65(14):5991-5995; discussion 5995.

68. Onder TT, Gupta PB, Mani SA, Yang J, Lander ES and Weinberg RA. Loss of E-cadherin promotes metastasis via multiple downstream transcriptional pathways. Cancer Res. 2008; 68(10):3645-3654.

69. Weinberg RA. The Biology of Cancer (Garland Science, New York). There is no corresponding record for this reference. 2007.

70. Matsuo N, Shiraha H, Fujikawa T, Takaoka N, Ueda N, Tanaka S, Nishina S, Nakanishi Y, Uemura M, Takaki A, Nakamura S, Kobayashi Y, Nouso K, Yagi T and Yamamoto K. Twist expression promotes migration and invasion in hepatocellular carcinoma. BMC Cancer. 2009; 9:240.

71. Yang $\mathrm{MH}$ and $\mathrm{Wu} \mathrm{KJ}$. TWIST activation by hypoxia inducible factor-1 (HIF-1): implications in metastasis and development. Cell Cycle. 2008; 7(14):2090-2096.

72. Yang MH, Hsu DS, Wang HW, Wang HJ, Lan HY, Yang WH, Huang CH, Kao SY, Tzeng CH, Tai SK, Chang SY, Lee $\mathrm{OK}$ and $\mathrm{Wu} \mathrm{KJ}$. Bmil is essential in Twist1-induced epithelial-mesenchymal transition. Nat Cell Biol. 2010; 12(10):982-992.

73. Craveiro V, Yang-Hartwich Y, Holmberg JC, Sumi NJ, Pizzonia J, Griffin B, Gill SK, Silasi D-A, Azodi M, Rutherford T, Alvero AB and Mor G. Phenotypic modifications in ovarian cancer stem cells following Paclitaxel treatment. Cancer Medicine. 2013:n/a-n/a.

74. Wang X, Ling MT, Guan XY, Tsao SW, Cheung HW, Lee DT and Wong YC. Identification of a novel function of TWIST, a bHLH protein, in the development of acquired taxol resistance in human cancer cells. Oncogene. 2004; 23(2):474-482.

75. Pham CG, Bubici C, Zazzeroni F, Knabb JR, Papa S, Kuntzen $C$ and Franzoso G. Upregulation of Twist-1 by NFkappaB blocks cytotoxicity induced by chemotherapeutic drugs. Mol Cell Biol. 2007; 27(11):3920-3935.
76. Mironchik Y, Winnard PT, Jr., Vesuna F, Kato Y, Wildes F, Pathak AP, Kominsky S, Artemov D, Bhujwalla Z, Van Diest P, Burger H, Glackin C and Raman V. Twist overexpression induces in vivo angiogenesis and correlates with chromosomal instability in breast cancer. Cancer Res. 2005; 65(23):10801-10809.

77. Kajiyama H, Hosono S, Terauchi M, Shibata K, Ino K, Yamamoto E, Nomura S, Nawa A and Kikkawa F. Twist expression predicts poor clinical outcome of patients with clear cell carcinoma of the ovary. Oncology. 2006; 71(56):394-401.

78. Yoshida J, Horiuchi A, Kikuchi N, Hayashi A, Osada R, Ohira S, Shiozawa $T$ and Konishi I. Changes in the expression of E-cadherin repressors, Snail, Slug, SIP1, and Twist, in the development and progression of ovarian carcinoma: the important role of Snail in ovarian tumorigenesis and progression. Med Mol Morphol. 2009; 42(2):82-91.

79. Elloul S, Vaksman O, Stavnes HT, Trope CG, Davidson B and Reich R. Mesenchymal-to-epithelial transition determinants as characteristics of ovarian carcinoma effusions. Clin Exp Metastasis. 2010; 27(3):161-172.

80. Wang WS, Yu SL, Yang XS, Chang SD and Hou JQ. Expression and significance of twist and E-cadherin in ovarian cancer tissues. Asian Pac J Cancer Prev. 2013; 14(2):669-672.

81. Li J, Wood WH, 3rd, Becker KG, Weeraratna AT and Morin PJ. Gene expression response to cisplatin treatment in drug-sensitive and drug-resistant ovarian cancer cells. Oncogene. 2007; 26(20):2860-2872.

82. Clarke MF, Dick JE, Dirks PB, Eaves CJ, Jamieson CH, Jones DL, Visvader J, Weissman IL and Wahl GM. Cancer stem cells--perspectives on current status and future directions: AACR Workshop on cancer stem cells. Cancer Res. 2006; 66(19):9339-9344.

83. Clarke MF and Fuller M. Stem cells and cancer: two faces of eve. Cell. 2006; 124(6):1111-1115.

84. Dean M, Fojo T and Bates S. Tumour stem cells and drug resistance. Nat Rev Cancer. 2005; 5(4):275-284.

85. Huang EH, Heidt DG, Li CW and Simeone DM. Cancer stem cells: a new paradigm for understanding tumor progression and therapeutic resistance. Surgery. 2007; 141(4):415-419.

86. Reya T, Morrison SJ, Clarke MF and Weissman IL. Stem cells, cancer, and cancer stem cells. Nature. 2001; 414(6859):105-111.

87. Yilmaz OH, Valdez R, Theisen BK, Guo W, Ferguson DO, $\mathrm{Wu} \mathrm{H}$ and Morrison SJ. Pten dependence distinguishes haematopoietic stem cells from leukaemia-initiating cells. Nature. 2006; 441(7092):475-482.

88. Rosen JM and Jordan CT. The increasing complexity of the cancer stem cell paradigm. Science. 2009; 324(5935):16701673.

89. Zhang S, Balch C, Chan MW, Lai HC, Matei D, Schilder 
JM, Yan PS, Huang TH and Nephew KP. Identification and characterization of ovarian cancer-initiating cells from primary human tumors. Cancer Res. 2008; 68(11):43114320.

90. Alvero AB, Chen R, Fu HH, Montagna M, Schwartz PE, Rutherford T, Silasi DA, Steffensen KD, Waldstrom M, Visintin I and Mor G. Molecular phenotyping of human ovarian cancer stem cells unravels the mechanisms for repair and chemoresistance. Cell Cycle. 2009; 8(1):158166.

91. Alvero $\mathrm{AB}, \mathrm{Fu} \mathrm{HH}$, Holmberg J, Visintin I, Mor L, Marquina CC, Oidtman J, Silasi DA and Mor G. Stemlike ovarian cancer cells can serve as tumor vascular progenitors. Stem Cells. 2009; 27(10):2405-2413.

92. Leizer AL, Alvero AB, Fu HH, Holmberg JC, Cheng YC, Silasi DA, Rutherford T and Mor G. Regulation of Inflammation by the NF-kappaB Pathway in Ovarian Cancer Stem Cells. Am J Reprod Immunol. 2011; 65(4):438-447.

93. Alvero AB, Montagna MK, Craveiro V, Liu L and Mor G. Distinct subpopulations of epithelial ovarian cancer cells can differentially induce macrophages and $\mathrm{T}$ regulatory cells toward a pro-tumor phenotype. Am J Reprod Immunol. 2012; 67(3):256-265.

94. Steffensen KD, Alvero AB, Yang Y, Waldstrom M, Hui P, Holmberg JC, Silasi DA, Jakobsen A, Rutherford T and Mor G. Prevalence of epithelial ovarian cancer stem cells correlates with recurrence in early-stage ovarian cancer. J Oncol. 2011; 2011:620523.

95. Alvero AB, Montagna MK, Chen R, Kim KH, Kyungjin K, Visintin I, Fu HH, Brown D and Mor G. NV-128, a novel isoflavone derivative, induces caspase-independent cell death through the Akt/mammalian target of rapamycin pathway. Cancer. 2009.

96. Mor G and Alvero A. The duplicitous origin of ovarian cancer. Rambam Maimonides medical journal. 2013; 4(1):e0006.

97. Bapat SA, Mali AM, Koppikar CB and Kurrey NK. Stem and progenitor-like cells contribute to the aggressive behavior of human epithelial ovarian cancer. Cancer Res. 2005; 65(8):3025-3029.

98. Gao Q, Geng L, Kvalheim G, Gaudernack G and Suo Z. Identification of cancer stem-like side population cells in ovarian cancer cell line OVCAR-3. Ultrastruct Pathol. 2009; 33(4):175-181.

99. Moserle L, Indraccolo S, Ghisi M, Frasson C, Fortunato E, Canevari S, Miotti S, Tosello V, Zamarchi R, Corradin A, Minuzzo S, Rossi E, Basso G and Amadori A. The side population of ovarian cancer cells is a primary target of IFN-alpha antitumor effects. Cancer Res. 2008; 68(14):5658-5668.

100. Szotek PP, Pieretti-Vanmarcke R, Masiakos PT, Dinulescu DM, Connolly D, Foster R, Dombkowski D, Preffer F, Maclaughlin DT and Donahoe PK. Ovarian cancer side population defines cells with stem cell-like characteristics and Mullerian Inhibiting Substance responsiveness. Proceedings of the National Academy of Sciences of the United States of America. 2006; 103(30):11154-11159.

101. Curley MD, Therrien VA, Cummings CL, Sergent PA, Koulouris CR, Friel AM, Roberts DJ, Seiden MV, Scadden DT, Rueda BR and Foster R. CD133 expression defines a tumor initiating cell population in primary human ovarian cancer. Stem Cells. 2009; 27(12):2875-2883.

102. Curley MD, Garrett LA, Schorge JO, Foster R and Rueda BR. Evidence for cancer stem cells contributing to the pathogenesis of ovarian cancer. Front Biosci. 2011; 16:368392.

103. Kurrey NK, K A and Bapat SA. Snail and Slug are major determinants of ovarian cancer invasiveness at the transcription level. Gynecol Oncol. 2005; 97(1):155-165.

104. Zhang S, Balch C, Chan MW, Lai HC, Matei D, Schilder JM, Yan PS, Huang TH and Nephew KP. Identification and characterization of ovarian cancer-initiating cells from primary human tumors. Cancer Res. 2008; 68(11):43114320.

105. Yin G, Alvero AB, Craveiro V, Holmberg JC, Fu HH, Montagna MK, Yang Y, Chefetz-Menaker I, Nuti S, Rossi M, Silasi DA, Rutherford T and Mor G. Constitutive proteasomal degradation of TWIST-1 in epithelial-ovarian cancer stem cells impacts differentiation and metastatic potential. Oncogene. 2013; 32(1):39-49.

106. Berchuck A, Elbendary A, Havrilesky L, Rodriguez GC and Bast RC, Jr. Pathogenesis of ovarian cancers. J Soc Gynecol Investig. 1994; 1(3):181-190.

107. Bast RC, Jr., Hennessy B and Mills GB. The biology of ovarian cancer: new opportunities for translation. Nat Rev Cancer. 2009; 9(6):415-428.

108. Vergara D, Merlot B, Lucot JP, Collinet P, Vinatier D, Fournier I and Salzet M. Epithelial-mesenchymal transition in ovarian cancer. Cancer Lett. 291(1):59-66.

109. Walsh CS and Karlan BY. Molecular signatures of ovarian cancer: from detection to prognosis. Mol Diagn Ther. 2010; 14(1):13-22.

110. Mani SA, Guo W, Liao MJ, Eaton EN, Ayyanan A, Zhou AY, Brooks M, Reinhard F, Zhang CC, Shipitsin M, Campbell LL, Polyak K, Brisken C, Yang J and Weinberg RA. The epithelial-mesenchymal transition generates cells with properties of stem cells. Cell. 2008; 133(4):704-715.

111. Thiery JP. Epithelial-mesenchymal transitions in development and pathologies. Curr Opin Cell Biol. 2003; 15(6):740-746.

112. Sabbah M, Emami S, Redeuilh G, Julien S, Prevost G, Zimber A, Ouelaa R, Bracke M, De Wever O and Gespach C. Molecular signature and therapeutic perspective of the epithelial-to-mesenchymal transitions in epithelial cancers. Drug Resist Updat. 2008; 11(4-5):123-151.

113. De Wever O, Pauwels P, De Craene B, Sabbah M, Emami S, Redeuilh G, Gespach C, Bracke M and Berx G. Molecular 
and pathological signatures of epithelial-mesenchymal transitions at the cancer invasion front. Histochem Cell Biol. 2008; 130(3):481-494.

114. Thiery JP and Sleeman JP. Complex networks orchestrate epithelial-mesenchymal transitions. Nat Rev Mol Cell Biol. 2006; 7(2):131-142.

115. Kajiyama H, Shibata K, Terauchi M, Yamashita M, Ino K, Nawa A and Kikkawa F. Chemoresistance to paclitaxel induces epithelial-mesenchymal transition and enhances metastatic potential for epithelial ovarian carcinoma cells. Int J Oncol. 2007; 31(2):277-283.

116. Latifi A, Abubaker K, Castrechini N, Ward AC, Liongue C, Dobill F, Kumar J, Thompson EW, Quinn MA, Findlay JK and Ahmed N. Cisplatin treatment of primary and metastatic epithelial ovarian carcinomas generates residual cells with mesenchymal stem cell-like profile. J Cell Biochem. 2011; 112(10):2850-2864. 